\title{
Underdiagnosis of chronic obstructive pulmonary disease: A rationale for spirometry as a screening tool
}

\author{
R Andrew Mclvor MD MSc FRCPC ${ }^{1}$, Donald P Tashkin MD ${ }^{2}$ \\ ${ }^{1}$ The Department of Respiratory Medicine, Dalhousie University, Halifax, Nova Scotia; and \\ ${ }^{2}$ Division of Pulmonary and Critical Care Medicine, University of California at Los Angeles \\ School of Medicine, Los Angeles, California, USA
}

RA McIvor, DP Tashkin. Underdiagnosis of chronic obstructive pulmonary disease: A rationale for spirometry as a screening tool. Can Respir J 2001;8(3):153-158.

Chronic obstructive pulmonary disease (COPD) is associated with significant morbidity and mortality. It is the fourth leading cause of death in the United States, and its impact on quality of life can be severe. The debate on spirometry as a screening tool has been raised and dropped on various occasions over the past 30 years. This paper readdresses the debate in the light of recent evidence from population studies. Spirometry is an underused, easy to perform office-based procedure that has been further facilitated by the advent of modern technology. Despite the fact that spirometry is the gold standard for the diagnosis and assessment of COPD, mass screening using this tool remains controversial. This article provides a discussion based on a recent review of the literature regarding the current and future status of spirometry as a screening tool. A thoughtful approach to spirometry screening should include assessments of the magnitude of underdiagnosis, potential effectiveness of intervention, predictive value of spirometry and clinical profile of patients with COPD.

Key Words: Chronic obstructive pulmonary disease; Screening; Spirometry

\section{La bronchopneumopathie obstructive chronique trop peu diagnostiquée : Justification de la spirométrie comme outil de dépistage}

\begin{abstract}
RÉSUMÉ : La bronchopneumopathie obstructive chronique (BPOC) est associée à un degré significatif de morbidité et de mortalité. Elle vient au quatrième rang des principales causes de décès aux ÉtatsUnis et son impact sur la qualité de vie peut être très grand. Le débat entourant le recours à la spirométrie comme outil de dépistage a tour à tour été repris puis abandonné depuis une trentaine d'années. Cet article ramène le sujet sur le tapis à la lumière des preuves récentes tirées d'études de populations. La spirométrie est une technique sous-utilisée, facile à effectuer au cabinet médical, qui est désormais facilitée par sa modernisation. En dépit du fait que la spirométrie constitue la norme pour le diagnostic et l'évaluation de la BPOC, le dépistage généralisé à l'aide de cet outil reste controversé. Cet article aborde le sujet à la lumière d'une récente synthèse de la littérature relative au statut actuel et futur de la spirométrie en tant qu'outil diagnostique. Dans une approche réfléchie sur l'utilisation de la spirométrie comme outil de dépistage, il faudrait évaluer dans quelle mesure la BPOC est sous-diagnostiquée, vérifier l'efficacité potentielle de l'intervention, mesurer la valeur prédictive de la spirométrie et dresser le profil clinique des patients atteints de BPOC.
\end{abstract}


$\mathrm{C}$ hronic obstructive pulmonary disease (COPD) is associated with significant morbidity and mortality. It is the fourth leading cause of death in the United States (1) and its impact on quality of life can be severe. Physicians have the opportunity to help patients escape the consequences of untreated COPD. It has not been proved that medication can alter the course of the disease, but smoking cessation produces impressive short and long term results, as was shown by the Lung Health Study $(2,3)$.

Some experts recommend spirometry screening to prevent underdiagnosis and to maximize the opportunity to intervene, as is done with hypertension (4). Mass screening remains controversial, however. It may result in overdiagnosis and overuse of health resources. Spirometry results have been shown to correlate with the development of COPD in men who smoke, but a similar correlation has been shown only variably in women $(2,5)$. 'Abnormal' spirometry readings based on predicted ideal values may cause undue alarm, while 'normal' readings in smokers may cause undue complacency. Finally, even aggressive intervention is unlikely to produce a high smoking cessation rate $(2,6)$, and the correlation between screening and cessation is uncertain (7).

Spirometry is well established as a necessary diagnostic tool (8). A thoughtful approach to spirometry screening should include assessments of the magnitude of underdiagnosis, the potential effectiveness of intervention, the predictive accuracy of spirometry and the clinical profile of COPD.

\section{EVIDENCE OF UNDERDIAGNOSIS}

It has long been believed that COPD is underdiagnosed; several factors contribute to this. COPD is often clinically indistinguishable from chronic asthma. The symptoms are similar: many asthmatics smoke or have smoked but are not necessarily smoke susceptible, and many patients with COPD have hyperreactive airways but are not necessarily asthmatic. Several studies have also shown that asthma, like COPD, is associated with an accelerated decline in lung function irrespective of smoking status (9-12).

The most likely reason for underdiagnosis, however, is that disabling COPD symptoms do not appear until the disease is well advanced and pulmonary function is significantly impaired. Wolkove and co-workers (13) have shown that statistically significant changes in forced expiratory volume in $1 \mathrm{~s}\left(\mathrm{FEV}_{1}\right)$ do not necessarily represent important differences in patients' symptoms. The same authors also demonstrated that the correlation between acute changes in spirometry values and dyspnea is weak (13). Thus, patients with an $\mathrm{FEV}_{1}$ that is significantly lower than the predicted normal value may not perceive symptoms related to airway limitation (14).

Results from a study in the United Kingdom indicate the magnitude of underdiagnosis (15). The authors surmised that chronic airways obstruction is underdiagnosed and undertreated in adults and the elderly. To test their hypothesis, they surveyed 783 men and women over the age of 45 years in the city of Manchester - an industrial centre. Survey respondents

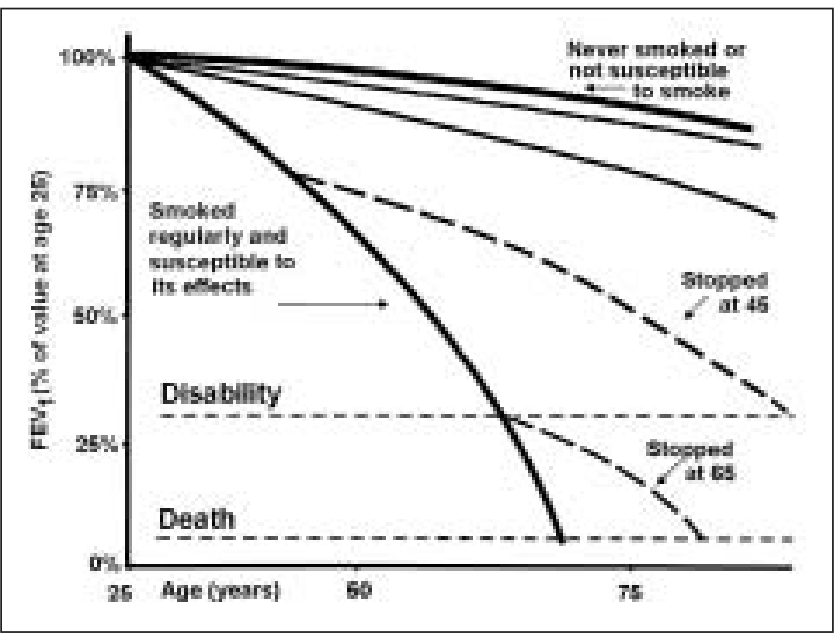

Figure 1) Fletcher and Peto (17) proposed the "horse-racing effect" in the rate of decline of lung function in smokers. Smokers who are not susceptible to smoke have a similar rate of decline to that of nonsmokers. Susceptible smokers do not begin to diverge significantly from nonsmokers until about 35 years of age after many years of smoking; from that point on, the fall in forced expiratory volume in $1 \mathrm{~s}\left(F E V_{1}\right)$ is precipitous. Adapted with permission from reference 17

were then invited to undergo pulmonary function tests and methacholine challenge. The overall response rate was $92.3 \%$; the mean age of the population was 66.1 years.

The study yielded several interesting results. The smoking rate was high: $29.2 \%$ of the respondents reported that they were current smokers and $37.3 \%$ were exsmokers. Reduced lung function may be the result of heavy smoking in the past as well as current smoking; the Manchester statistics suggest that a large number of older adults are at risk. Indeed, the prevalence of COPD was high. Evidence of chronic airway obstruction was found in $26.4 \%$ of the 247 respondents who were evaluated with spirometry. Of these, $76.6 \%$ reported respiratory symptoms, yet only $55.4 \%$ had received a diagnosis of asthma or chronic bronchitis. The results indicate that many more individuals have both respiratory symptoms and objectively observable chronic obstruction than are diagnosed. These findings have serious implications for underdiagnosis in younger populations, who are typically asymptomatic. In most COPD patients, dyspnea does not appear until the sixth or seventh decade of life, and yet the underlying pathophysiological causes may already be well established by 40 years of age. The Manchester study indicated that underdiagnosis is evident even in older symptomatic patients, and, therefore, it is reasonable to assume that a large number of younger asymptomatic patients do not receive a diagnosis of their condition until it is well advanced.

The Manchester study also showed evidence of undertreatment. Only $36.9 \%$ of patients with observable airway obstructions were using inhaled bronchodilators or steroids. Similar results were reported by Bodner et al (16), who studied the prevalence of adult-onset wheeze in Aberdeen, Scotland. A follow-up questionnaire was issued to 1758 adults aged 39 to 45 years who had been surveyed 31 years earlier for 
asthma. Adult-onset wheeze was reported by $11.5 \%$ of the respondents. Of these, $63.2 \%$ were past or current smokers, suggesting that chronic bronchitis may have been an underlying cause of respiratory symptoms even in a relatively young population. Of respondents who reported that their symptoms were limiting their activities, over $40 \%$ were not receiving treatment.

\section{EFFECTIVENESS OF INTERVENTION}

Smoking is by far the most significant risk factor for COPD, and its effects are potentiated by age. As described by Fletcher and Peto (17), FEV 1 in susceptible smokers does not begin to diverge significantly from the normal range of decline until about 35 years of age, typically after 20 years or more of smoking, but then falls precipitously compared with normal values (the "horse-racing effect", Figure 1). Fletcher et al (18) developed the horse-racing analogy to suggest that those with the worst function (ie, lowest $\mathrm{FEV}_{1}$ ) at a single observation are deteriorating more rapidly before measurement and will continue to do so. The underlying pathophysiology associated with smoking appears to gather momentum with age. Smoking cessation at any point along the acceleration curve results in normalization of the rate of decline in lung function. Thus, it seems logical to intervene as early as possible.

The Lung Health Study showed the beneficial effects of early intervention $(2,19)$. The five-year multiclinical study comprised 5887 smokers with mild to moderate airflow limitation in the United States and Canada. Its purpose was to determine whether smoking intervention and the use of a bronchodilator would slow the rate of decline in $\mathrm{FEV}_{1}$ in early COPD. As seen in Figure 2, successful intervention had remarkable benefits on lung function. Sustained quitters showed absolute improvement at one year, and the benefit continued to increase over the five years of the study compared with the results in continuing smokers. The investigators concluded that smoking cessation results in a substantial benefit to lung function and is the most important intervention in smokers with mild COPD.

The Lung Health Study also showed the benefit of proactive smoking intervention in patients with mild COPD. The sustained quit rate in the special (active) intervention group over five years was $22 \%$ compared with only $5 \%$ in the usual care (control) group. According to the investigators, the sustained rate of $22 \%$ was among the highest ever reported for a major study. The rate still seems discouragingly low, however, considering that patients were fully apprised of the serious implications of their spirometry results and underwent an intensive 12-week smoking cessation program, followed by an aggressive relapse prevention program throughout the remainder of the five-year study. While the study was certainly a "triumph" (20) in its demonstration of the benefits of smoking cessation in patients with mild COPD, it neither showed that spirometry results themselves are a significant motivating factor in sustained smoking cessation nor, conversely, did it evaluate whether the finding of normal spirometric values might encourage smokers in their habit. Moreover, the Lung Health Study's limited objective of screening smokers

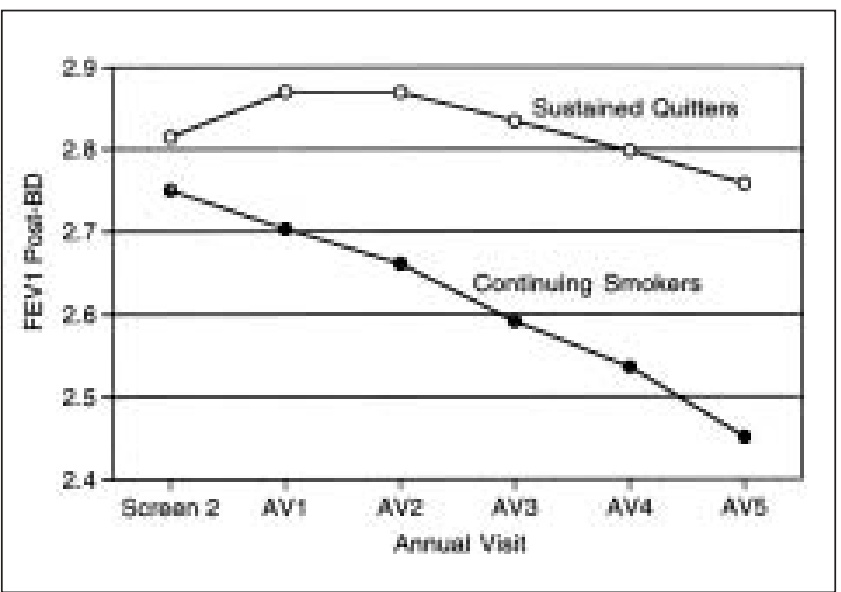

Figure 2) The effect of smoking intervention in the Lung Health Study (2) is shown. Sustained quitters exhibited absolute improvement in forced expiratory volume in $1 s\left(F E V_{l}\right)$ at one year, and the subsequent rate of decline in FEV 1 improved throughout the five-year observation period compared with that of continuing smokers. BD Bronchodilator. Reproduced with permission from reference 2. Copyrighted 1994, American Medical Association

over the age of 35 years did not afford an opportunity to assess the social usefulness of mass spirometry screening in the general population at risk.

\section{PREDICTIVE ACCURACY OF SPIROMETRY}

Spirometry is objective and quantifiable, and can detect airflow limitation well before symptoms appear. Although patients with confirmed COPD have a low FEV 1 compared with age-adjusted normal values, this measurement alone may not be predictive of COPD (5). A more accurate indicator is the ratio of $\mathrm{FEV}_{1}$ to forced vital capacity (FVC). An $\mathrm{FEV}_{1}$ to $\mathrm{FVC}$ ratio of less than $70 \%$ is generally acknowledged to indicate the presence of airflow limitation, even in the absence of physical evidence or symptoms. It is of interest that all participants in the Lung Health Study had an $\mathrm{FEV}_{1}$ to FVC ratio less than $70 \%$, while the mean $\mathrm{FEV}_{1}$ at study entry in these same individuals (75\% predicted) was only slightly below the lower limit of normal, and a large proportion of the subjects had an $\mathrm{FEV}_{1}$ that was statistically within normal limits (2).

The importance of spirometry was demonstrated in a study by van Schayck et al (21), who evaluated whether the progression of asthma or chronic bronchitis can be predicted by family physicians apart from lung function testing. They compared physical examination and peak flow results with $\mathrm{FEV}_{1}$ as indicators of decline. In chronic bronchitis, only $27 \%$ of the variance in $\mathrm{FEV}_{1}$ decline could be explained by the results of both the chest examination and the diurnal variation in peak flow rate. The authors concluded that it is difficult, if not impossible, to predict the rate of decline in obstructive airway disease through physical examination alone.

While a strong association between an $\mathrm{FEV}_{1}$ to $\mathrm{FVC}$ ratio of less than $70 \%$ and accelerated decline in $\mathrm{FEV}_{1}$ has been seen in male smokers, Burrows and colleagues (5) observed no such clear relation in women. On the other hand, in the Lung 
TABLE 1

Clinical profile of asymptomatic chronic obstructive pulmonary disease

\begin{tabular}{ll}
\hline Risk factor & References \\
\hline Smoking history & Anthonisen et al (2) \\
& Sherrill et al (35) \\
& Buist and Ducic (26) \\
Age (35 years and older) & Anthonisen et al (2) \\
& Fletcher and Peto (17) \\
& Burrows et al (5) \\
Methacholine reactivity & Tashkin et al (22) \\
& Vollmer et al (36) \\
& Barter and Campbell (37) \\
Environmental exposures & Tashkin et al (28) \\
& Oxman et al (27) \\
& Becklake (38) \\
\hline
\end{tabular}

Health Study, in which over one-third of the participants were women, baseline $\mathrm{FEV}_{1}$ was found to be a significant predictor of subsequent decline in $\mathrm{FEV}_{1}$ in both male and female continuing smokers (22). In the same study, interestingly, methacholine reactivity (although not an appropriate choice as a screening tool) at the start of the trial was found to be a particularly strong predictor of deteriorating lung function in smokers, regardless of baseline lung function. Furthermore, women with borderline to moderate airflow limitation were found to be significantly more reactive than men (23). The sex differences were independent of differences in age, cigarette use or asthma; they were largely explained by the lower absolute $\mathrm{FEV}_{1}$ in women, which was felt to be a surrogate for a smaller airway calibre (24).

\section{COPD CLINICAL PROFILE}

The Lung Health Study showed that spirometry screening in a selected population is an effective way to identify individuals at risk for COPD and to initiate effective interventions. Thus, it seems reasonable to conclude that a clinical profile of asymptomatic COPD can make screening feasible (Table 1).

Smoking is the key attribute of such a profile. In the Lung Health Study, smoking cessation led to initial absolute improvement of lung function and subsequent improvement in the rate of decline, whereas a steep rate of decline was seen in those who continued to smoke. Of the 73,694 smokers who were screened for COPD in this study, about $25 \%$ met the criteria for mild to moderate airflow obstruction $\left(\mathrm{FEV}_{1}\right.$ to $\mathrm{FVC}$ ratio of less than 70\%) (25). This prevalence is high compared with that reported in other studies (26) but correlates well with the results of the Manchester study described above. It is of interest to note that participants in the study tended to be heavy smokers - 20 to 30 cigarettes/day.

The high prevalence of COPD among smokers suggests other possible inclusion criteria for screening, particularly because methacholine reactivity was a strong predictor of decline in lung function in the Lung Health Study (22). A study by Oxman et al (27) indicated that exposure to occupational dust is a significant risk factor for COPD. Environment may also play a role: a population study in southern California showed that chronic exposure to air pollution has an independent adverse effect on lung function in male smokers and possibly in female smokers, and that this effect is additive to that of smoking (28).

As discussed above, age is also a risk factor for airway obstruction and is probably the key reason for underdiagnosis. Physicians are trained to evaluate symptomatic disease, but the dyspnea associated with COPD may not become evident to the patient until 50 years of age or later, and acute exacerbations of bronchitis may not occur until the 40s. The challenge, then, is to identify a reasonable age for COPD screening. The Lung Health Study used 35 years of age as its lower limit; this choice was justified by the relatively high proportion of patients aged 35 to 39 years (12\%) included in the trial. It is possible, however, that COPD is detectable in even younger patients. In a study of tobacco and marijuana smokers with an average age of 33 years, about $25 \%$ had chronic cough and sputum production, $35 \%$ had wheeze and $10 \%$ had at least one acute bronchitis attack per year (29).

That even younger patients may be symptomatic is a reminder that spirometry screening is not an absolute substitute for the medical history and a physical examination. As demonstrated by Badgett and co-workers (30), moderate COPD can be diagnosed by internists with reasonable accuracy using breath sounds and the patient's history. Holleman and Simel (31) reviewed the predictive value of clinical examination and concluded that the clinician's ability to diagnose airflow limitation is variable but seems to improve as the severity of the disorder increases.

\section{A MATRIX FOR SPIROMETRY SCREENING?}

In 1983, the American Thoracic Society issued a position statement discouraging population screening for COPD (32). There were two main objections. First, it was felt that a positive 'one-to-one' correlation between decreased lung function in smokers and future development of COPD had not been adequately shown. A perfect correlation is rare in preventive medicine, but it can be argued that the association between decreased lung function and smoking that was established in the Lung Health Study is as sound as that between coronary artery disease and hypertension. The second objection was that the screening test must be able to detect disease at a point where effective intervention can affect the outcome. Again, the resounding success of smoking intervention in mild COPD in the Lung Health Study should adequately address any such concerns.

At the same time, the Lung Health Study does not provide a rationale for mass population screening or even for screening in all smokers. Because it was well known that decreased lung function predictive of COPD can be observed in smokers in their 30s, 35 years of age was used as a cut-off point for screening. Thus, the results of the study provide justification for surveillance spirometry in a specific population at risk. At the same time, the study confirms that COPD is underdiagnosed: only $30 \%$ of those identified by spirometry screening as having mild COPD had received a diagnosis of 


\section{TABLE 2}

\section{Target populations for spirometry screening}

All smokers 35 years of age and older

Current or past smokers with a 20 pack-year history of smoking, whether or not the patient complains of respiratory symptoms

Patients with recurrent or chronic respiratory symptoms including cough and breathlessness on exertion

Patients who have significant occupational exposure to respiratory irritants

Patients with a family history of obstructive pulmonary disease

Patients with a history of hyper-responsiveness to provocative agents

Patients with childhood factors that may be associated with the development of chronic obstructive pulmonary disease: low birth weight, frequent respiratory infections, exposure to environmental tobacco smoke

If initial spirometry is normal. Risk factor modification (eg, smoking cessation). Repeat spirometry in three to five years or earlier if patient presents with respiratory symptoms

"bronchitis" from their physician (2). It also shows that early detection can lead to highly successful intervention.

Recently, Chan et al (33) looked at spirometry use in Ontario and reported a rapid increase in its use due to the diffusion of inexpensive spirometers in physicians' offices and an increased awareness of guidelines promoting objective testing. However, there was a wide regional variation in spirometry use. A corresponding editorial by Anthonisen

\section{REFERENCES}

1. American Thoracic Society. Standards for the diagnosis and care of patients with chronic obstructive pulmonary disease. Am J Respir Crit Care Med 1995;152:S77-121.

2. Anthonisen NR, Connett JE, Kiley JP, et al. Effects of smoking intervention and the use of an inhaled anticholinergic bronchodilator on the rate of decline of $\mathrm{FEV}_{1}$ : The Lung Health Study. JAMA 1994;272:1497-505.

3. Scanlon PD, Connett JE, Waller LA, Altose MD, Bailey WC, Buist AS. Smoking cessation and lung function in mild-to-moderate chronic obstructive pulmonary disease: The Lung Health Study. Am J Respir Crit Care Med 2000;161:381-90.

4. Petty TL. Test your lungs. Chest 1976;70:450-1.

5. Burrows B, Knudson RJ, Camilli AE, Lyle SK, Labowitz MD. The "horse-racing effect" and predicting decline in forced expiratory volume in one second from screening spirometry. Am Rev Respir Dis 1987;135:788-93.

6. Pederson LL, Williams JI, Lefcoe NM. Smoking cessation among pulmonary patients as related to type of respiratory disease and demographic variables. Can J Public Health 1980;71:191-4.

7. Loss RW, Hall WJ, Speers DM. Evaluation of early airway disease in smokers: cost effectiveness of pulmonary function testing. Am J Med Sci 1979;278:27-37.

8. Crapo RO. Pulmonary-function testing. N Engl J Med 1994;331:25-30.

9. Peat JK, Woolcock AJ, Cullen K. Rate of decline of lung function in subjects with asthma. Eur J Respir Dis 1987;70:171-9.

10. Lange P, Parner J, Vestbo J, Schnohr P, Jensen G. A 15-year follow-up study of ventilatory function in adults with asthma. N Engl J Med 1998;339:1194-200.

11. Ulrik CS, Lange P. Decline of lung function in adults with bronchial asthma. Am J Respir Crit Care Med 1994;150:629-34.

12. Burrows B, Boom JW, Traver GA, Cline MG. The course and prognosis of different forms of chronic airways obstruction in a sample from the general population. N Engl J Med 1987;317:1309-14.

13. Wolkove N, Dajczman E, Colacone A, Kreisman H. The relationship between pulmonary function tests and dyspnea in obstructive lung disease. Chest 1989;96:1247-51.
(34) suggested that these overall rates of use were a blunt instrument for health care utilization analysis. What we really need to know is whether the right patients are being screened, diagnosed or followed with this tool.

A reasonable approach for surveillance spirometry based on the results of the Lung Health Study is to screen all smokers over 35 years of age. If this model seems too onedimensional, COPD screening can also be conceived in the context of a matrix that sifts a few straightforward risk factors with the complex pathophysiology of the disease. Smoking is the major risk factor for COPD, but only a small percentage of smokers are at risk. Age is a factor, but significant airway limitation may be present in younger, asymptomatic patients. Methacholine reactivity is a factor, but it is linked to smoking and airflow limitation and does not necessarily indicate an 'asthmatic constitution'. Similarly, occupational and environmental irritants may be risk factors, but especially so in individuals who smoke. Target populations for whom spirometry screening is recommended are listed in Table 2.

\section{CONCLUSIONS}

Underdiagnosis of COPD represents a missed opportunity for early intervention. Although the Lung Health Study did not address the issue of mass screening, its results provide a compelling rationale for screening that is targeted to populations at risk.

14. Redelmeier DA, Goldstein RS, Min ST, Hyland RH. Spirometry and dyspnea in patients with COPD: When small differences mean little. Chest 1996;109:1163-8.

15. Renwick DS, Connolly MJ. Prevalence and treatment of chronic airways obstruction in adults over the age of 45. Thorax 1996;51:164-8.

16. Bodner C, Ross S, Douglas G, et al. The prevalence of adult onset wheeze: longitudinal study. BMJ 1997;314:792-3.

17. Fletcher CM, Peto R. The natural history of chronic airflow obstruction. BMJ 1977;i:1645-8.

18. Fletcher CM, Peto R, Tinker C, Speizer FE. The Natural History of Chronic Bronchitis and Emphysema. New York: Oxford University Press, 1976.

19. Kanner RE, Connett JE, Williams DE, Buist AS. Effects of randomized assignment to a smoking cessation intervention and changes in smoking habits on respiratory symptoms in smokers with early chronic obstructive pulmonary disease: the Lung Health Study. Am J Med 1999;106:410-6.

20. Gross NJ. The Lung Health Study: Disappointment and triumph. JAMA 1994;272:1539-41.

21. van Schayck CP, Dompeling E, Putters R, Molema J, van Weel C. Asthma and chronic bronchitis: Can family physicians predict rates of progression? Can Fam Physician 1995;41:1868-76.

22. Tashkin DP, Altose MD, Connett JE, Kanner RE, Lee WW, Wise RA, on behalf of the Lung Health Study Research Group. Methacholine reactivity predicts changes in lung function over time in smokers with early chronic obstructive pulmonary disease. Am J Respir Crit Care Med 1996;153:1802-11.

23. Tashkin DP, Altose MD, Bleecker ER, et al, on behalf of the Lung Health Study Research Group. The Lung Health Study: Airway responsiveness to inhaled methacholine in smokers with mild to moderate airflow limitation. Am Rev Respir Dis 1992;145:301-10.

24. Kanner RE, Connett JE, Altose MD, et al. Gender difference in airway hyperresponsiveness in smokers with mild COPD. The Lung Health Study. Am J Respir Crit Care Med 1994;150:956-61.

25. Buist AS, Connett JE, Miller RD, Kanner RE, Owens GR, Voelker HT. Chronic Obstructive Pulmonary Disease Early Intervention Trial (Lung Health Study): Baseline characteristics of randomized participants. Chest 1993;103:1863-72. 
26. Buist AS, Ducic S. Smoking: Evaluation of studies which have demonstrated pulmonary function changes. In: MacKlem PT, Permutt S, eds. The Lung in the Transition Between Health and Disease. New York: Marcel Dekker Inc, 1979:271-86.

27. Oxman AD, Muir DC, Shannon HS, Stock SR, Hnizdo E, Lange HJ. Occupational dust exposure and chronic obstructive pulmonary disease. A systematic overview of the evidence. Am Rev Respir Dis 1993;148:38-48.

28. Tashkin DP, Detels R, Simmons M, et al. The UCLA population studies of chronic obstructive respiratory disease: XI. Impact of air pollution and smoking on annual change in forced expiratory volume in one second. Am J Respir Crit Care Med 1994;149:1209-17.

29. Tashkin DP, Coulson AH, Clark VA, et al. Respiratory symptoms and lung function in habitual heavy smokers of marijuana alone, smokers of marijuana and tobacco, smokers of tobacco alone, and nonsmokers. Am Rev Respir Dis 1987;135:209-16.

30. Badgett RG, Tanaka DJ, Hunt DK, et al. Can moderate chronic obstructive pulmonary disease be diagnosed by historical and physical findings alone? Am J Med 1993;94:188-96.
31. Holleman DR Jr, Simel DL. Does the clinical examination predict airflow limitation? JAMA 1995;273:313-9.

32. Screening for adult respiratory disease. Official American Thoracic Society statement March 1983. Am Rev Respir Dis 1983;128:768-74.

33. Chan B, Anderson G, Dales RE. Spirometry utilization in Ontario: practice patterns and policy implications. CMAJ 1997;156:169-76.

34. Anthonisen NR. Spirometric testing: How much is enough? CMAJ 1997;156:202-4

35. Sherrill DL, Lebowitz MD, Burrows B. Epidemiology of chronic obstructive pulmonary disease. Clin Chest Med 1990;11:375-87.

36. Vollmer WM, Johnson LR, Buist AS. Relationship of response to a bronchodilator and decline in forced expiratory volume in one second in population studies. Am Rev Respir Dis 1985;132:1186-93.

37. Barter CE, Campbell AH. Relationship of constitutional factors and cigarette smoking to decrease in 1-second forced expiratory volume. Am Rev Respir Dis 1976;113:305-14.

38. Becklake MR. Chronic airflow limitation: its relationship to work in dusty occupations. Chest 1985;88:608-17. 


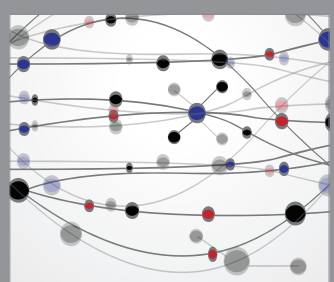

The Scientific World Journal
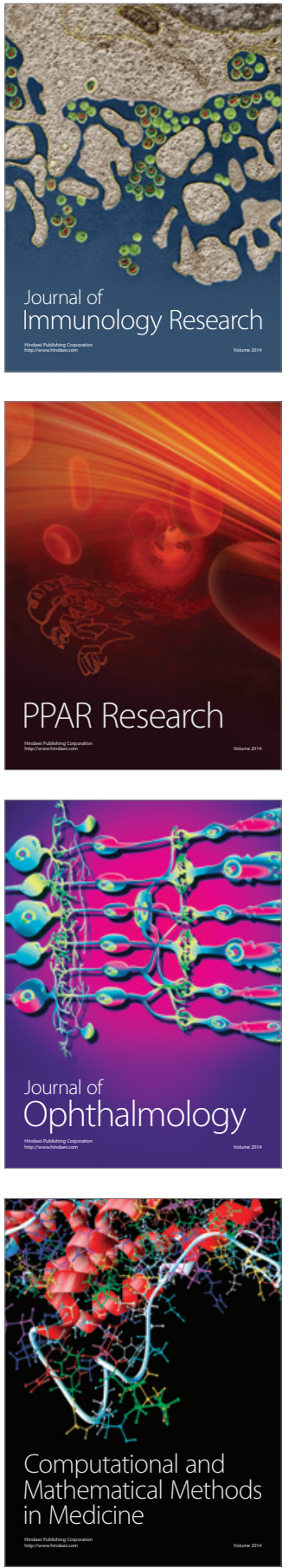

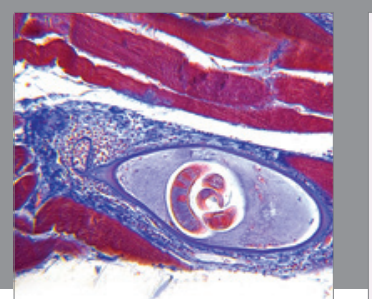

Gastroenterology Research and Practice

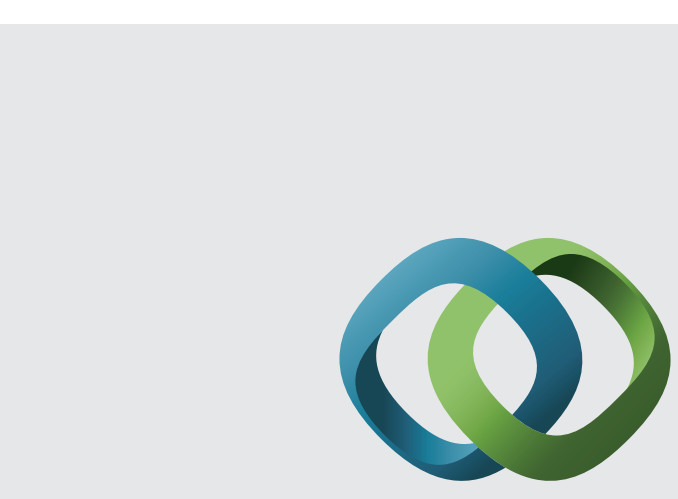

\section{Hindawi}

Submit your manuscripts at

http://www.hindawi.com
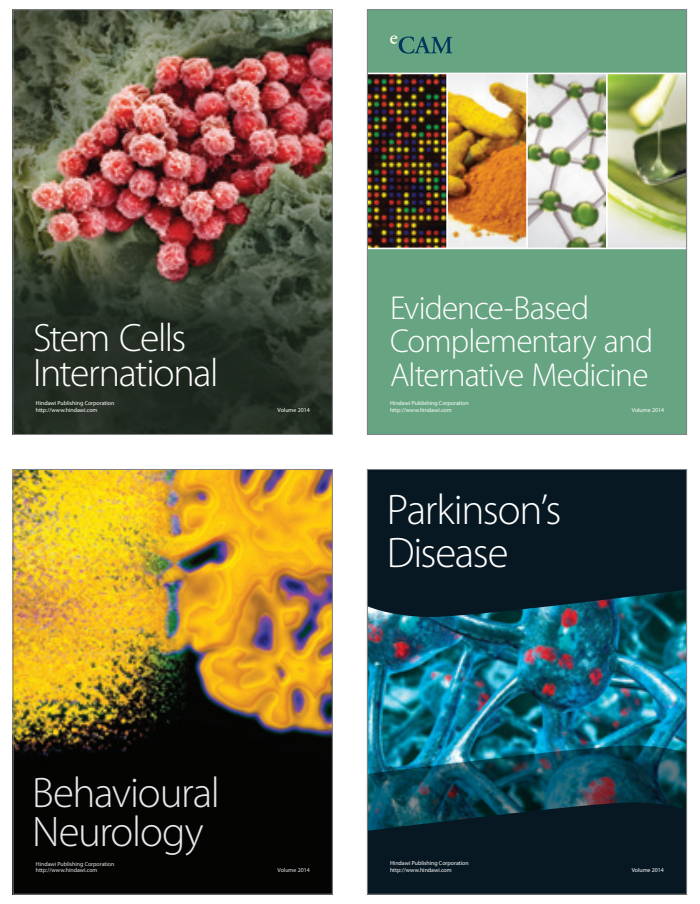
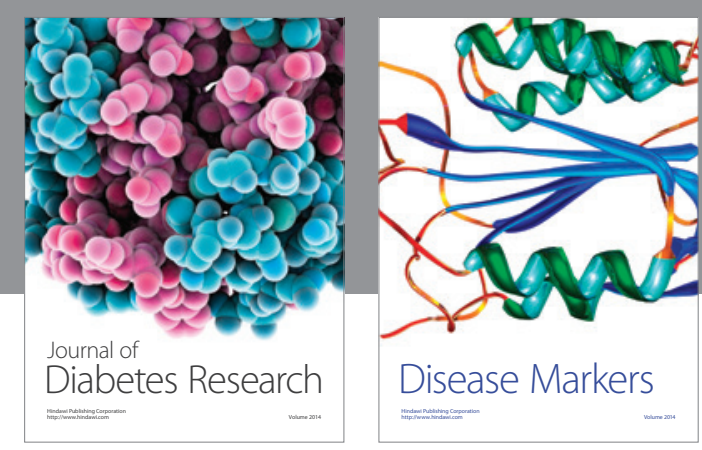

Disease Markers
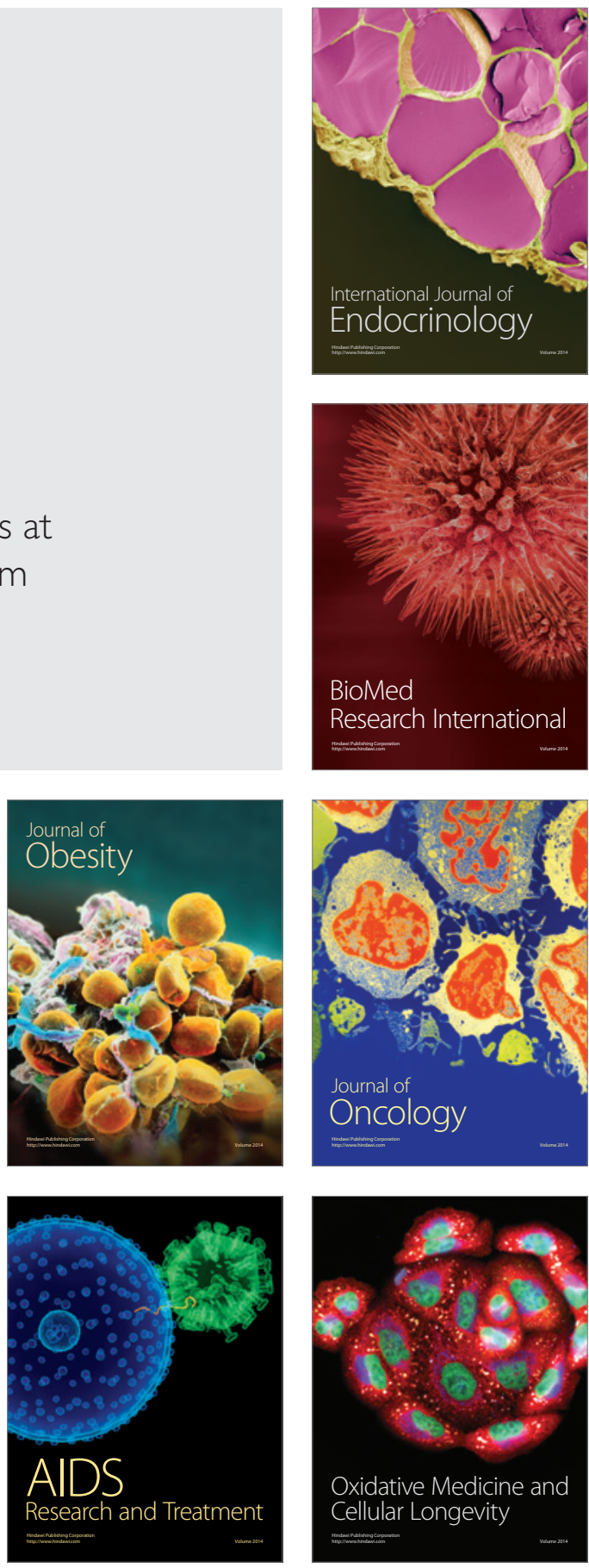